VOLUME 37, ARTICLE 39, PAGES 1297-1326 PUBLISHED 20 OCTOBER 2017

http://www.demographic-research.org/Volumes/Vol37/39/

DOI: $\quad$ 10.4054/DemRes.2017.37.39

Research Article

Decomposing changes in household measures:

Household size and services in South Africa, 1994-2012

\title{
Martin Wittenberg
}

Mark Collinson

\section{Tom Harris}

(c) 2017 Martin Wittenberg, Mark Collinson \& Tom Harris.

This open-access work is published under the terms of the Creative Commons Attribution NonCommercial License 2.0 Germany, which permits use, reproduction \& distribution in any medium for non-commercial purposes, provided the original author(s) and source are given credit. See http://creativecommons.org/licenses/by-nc/2.0/del 


\section{Contents}

$\begin{array}{llr}1 & \text { Introduction } & 1298\end{array}$

2 Households, change, and measurement in national surveys 1300

$2.1 \quad$ The concept of the household 1300

2.2 Household change and household services in South Africa 1302

2.3 Measurement of household change 1303

3 Decomposing shifts in household outcomes using longitudinal data 1305

4 Data 1306

4.1 Data requirements 1306

4.2 Demographic surveillance data $\quad 1307$

4.2.1 The Agincourt site 1307

4.2.2 The Health and Demographic Surveillance System (HDSS) 1308

4.2.3 Tracking households over time 1309

$\begin{array}{llr}4.3 & \text { Household panels } & 1309\end{array}$

4.3.1 The National Income Dynamics Study (NIDS) 1310

4.3.2 Tracking households in NIDS 1310

5 Methods $\quad 1312$

$\begin{array}{lll}5.1 & \text { Changes in household size } & 1312\end{array}$

Electricity connections $\quad 1312$

$6 \quad$ Results $\quad 1313$

6.1 Changes in household size 1313

6.2 Changes in household energy connections 1317

7 Conclusion: Households and social dynamics 1321

$8 \quad$ Acknowledgements 1321

References 1323 


\title{
Decomposing changes in household measures: Household size and services in South Africa, 1994-2012
}

\author{
Martin Wittenberg ${ }^{1}$ \\ Mark Collinson ${ }^{2}$ \\ Tom Harris ${ }^{3}$
}

\begin{abstract}
BACKGROUND

Household trends are generally tracked by means of repeated cross-sections, such as censuses or nationally representative surveys. However, the trends may be driven either by changes within households over time or the way in which the processes of household formation/dissolution interact with the measure in question.
\end{abstract}

\section{OBJECTIVE}

We aim to develop a method that enables us to apportion changes in a household measure to changes that happen within households and changes that occur due to household formation and dissolution. In particular we intend to show how South African households have reduced in size and how access to services has increased.

\section{METHODS}

We develop a formula for decomposing a household outcome measure. We apply the formula to household size and electricity access data from the Agincourt health and demographic surveillance site for the period 1994 to 2012. We also apply it to the National Income Dynamics Survey of South Africa from 2008 to 2012. We compare the results to the pattern derived from nationally representative surveys run by Statistics South Africa since 1994.

\section{RESULTS}

The overall reduction in household size is fuelled by rapid household formation, much of which is intertwined with shifts in location. Access to services has been reduced by

\footnotetext{
${ }^{1}$ School of Economics and DataFirst, University of Cape Town, South Africa.

E-Mail: martin.wittenberg@uct.ac.za.

${ }^{2}$ MRC/Wits University Rural Public Health and Health Transitions Research Unit, School of Public Health, University of Witwatersrand, South Africa; INDEPTH Network, Ghana; DST/SAMRC South African Population Research Infrastructure Network (SAPRIN).

${ }^{3}$ DataFirst, University of Cape Town, South Africa.
} 
Wittenberg, Collinson \& Harris: Decomposing changes in household measures

the process of new household formation. Neither finding is evident from cross-sectional data.

\section{CONTRIBUTION}

We introduce a new decomposition technique which can be used with longitudinal data and discuss the insights that it provides.

\section{Introduction}

South Africa has seen many profound changes since the end of apartheid. Many of these are documented through national censuses or nationally representative surveys. A case in point is average household size, the evolution of which is shown in Figure 1. It suggests that between the late 1990s and 2012 households lost, on average, one full member. Since household size is a ratio of two variables, total population and number of households, this reduction can occur due to changes in the numerator, population (e.g., increased mortality due to the HIV pandemic) or the denominator, number of households (e.g., new household formation). It is of considerable interest to identify the mechanisms through which this occurs; e.g., are households getting smaller because large extended households in rural areas are splitting into smaller units, or is it due to increasing mortality within households?

Another example where aggregate trends are provocative but insufficiently informative is given by Figure 2. According to two independently conducted national surveys (the General Household Survey and the National Income Dynamics Study), it appears that the mean connection rate to the electricity grid went down between 2008 and 2010 . This trend could be due to households getting disconnected or due to a burst of informal settlement construction sufficient to reduce the mean rate without anyone losing a connection.

In both cases we need to think about the possibility that aggregate trends are affected as much by the processes of household formation and dissolution as by what happens within households. In economics a distinction is often made between changes driven by the 'extensive margin' (entry/exit into a market) as opposed to changes occurring at the 'intensive margin' (by those within). For many household-level changes, it seems equally important to understand developments at these two margins. In this paper we will present a simple decomposition technique that shows how one might begin to think about the relative contribution of these margins to the aggregate pattern. In order to implement it, however, we require panel data, since we need to distinguish existing households from newly formed and dissolving ones. We will therefore also pay some attention to the types of data required in order to use the decomposition. 


\section{Figure 1: Average household size in South Africa, according to national household surveys}

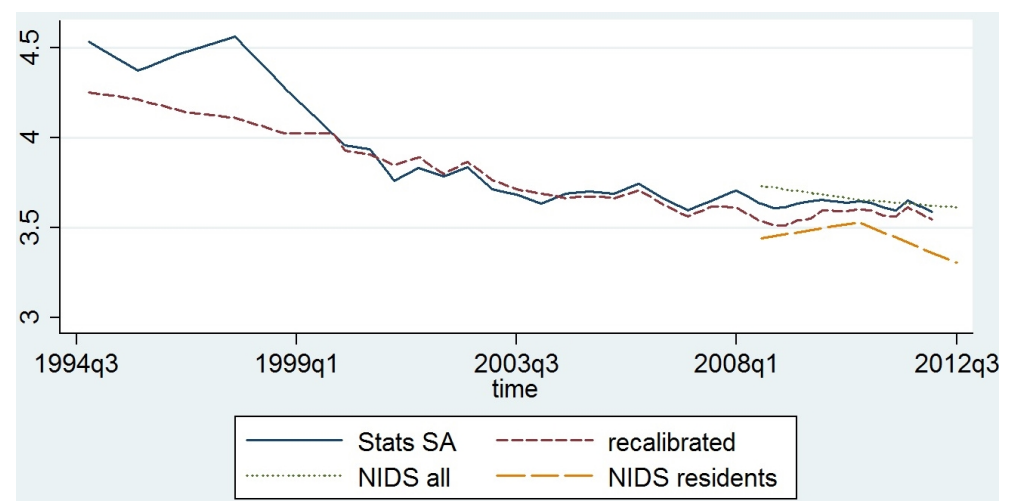

Note: Own calculations from the following sources: Stats SA (Statistics South Africa national sample surveys): October Household Surveys 1994-1999, Labour Force Surveys 2000-2007, and Quarterly Labour Force Surveys 2008-2012. Recalibrated: as for Stats SA and correcting for undersampling of small households. NIDS all (National Income Dynamics Study): all members including absent ones. NIDS residents: as for NIDS, resident household members only.

The structure of the paper is as follows: We begin by reviewing some of the literature dealing with measuring household change in general and the South African context in particular. We then present and discuss the decomposition. We apply it to two datasets: data from the Health and Demographic Surveillance System collected by the Medical Research Council (MRC)/Wits Rural Public Health and Health Transitions Research Unit (Agincourt) in a rural part of South Africa and the National Income Dynamics Study (NIDS) collected by the Southern Africa Labour and Development Research Unit. The former gives us a long run (since 1992) of high-quality panel data on a small area of South Africa, while the latter gives us a more recent (since 2008) nationally representative picture. Both are useful checks on the cross-sectional information coming from national surveys. We will apply the decomposition to the changes in household size and changes in electricity access. We will argue that our understanding of the national aggregate patterns revealed in Figures 1 and 2 are significantly enhanced by our decomposition. Virtually all of the drop in household size is due to changes at the dissolution/formation margin. In the case of electricity access most of the positive increase is due to increasing access within continuing households - but the rapid rate of new household formation has undercut some of these gains. Furthermore, our decomposition reveals a few anomalous patterns: cases where households lose connections and where people seem to be leaving better serviced locations in favour of less serviced ones. 
Figure 2: The proportion of South African households with an electricity connection according to nationally representative household surveys: the General Household Survey (GHS) and the National Income Dynamics Survey (NIDS)

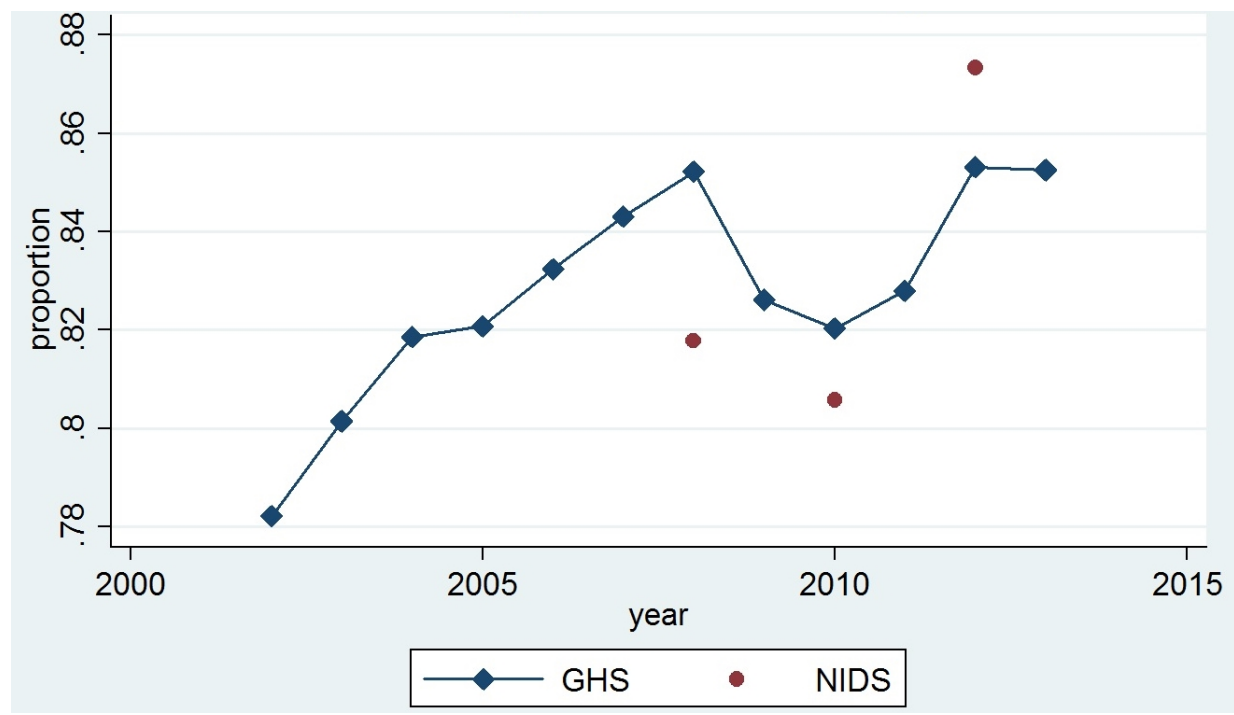

Note: Own calculations from GHS and NIDS.

\section{Households, change, and measurement in national surveys}

\subsection{The concept of the household}

The concept of the household is central to much social scientific research. Indeed Udjo (2015: 1510) notes that, "From a demographic standpoint, households constitute the unit of sampling in multistage sampling." So it isn't possible to evaluate the findings of social surveys without a solid grasp of what a household is. Nevertheless, the concept is not straightforward. For instance, in the introduction to a book dealing with postapartheid families and households (Amoateng and Heaton 2007), Amoateng and Richter (2007: 1), refer to "families, and their residential dimension, households." This sliding between 'families' and 'households' also occurs in Amoateng's (2007) theoretical discussion of these concepts. In that article he makes the point that these need to be understood against the backdrop of how all institutions connect within the overall social system. So, for instance, it is important to note the context of migrant labour and the restrictions on urban living space for the shape that African families took in urban areas during the apartheid 
era. One of the key debates in this context is whether the changing social environment in postapartheid South Africa is encouraging the African family to become more "nuclear" or "westernised" (Ziehl 2001; Amoateng and Kalule-Sabiti 2008). Amoateng, Heaton, and Kalule-Sabiti (2007) discuss changes in the living arrangements between 1996 and 2001. They note an increase in the number of single person households (which are more closely associated with 'Western' norms) but also note the continued relevance of complex household types. Indeed they speculate that the latter types of living arrangements may become more prevalent as some households become richer and no longer need to economise on space. Wittenberg and Collinson (2007) also note that 'complex' households are persisting and may even become more common over time. They reach this conclusion using longitudinal data and tracking transitions between household types. However, they do not find any tendency towards an increase in single person households in the rural area that they analyse.

One of the problems with the census information that Amoateng, Heaton, and KaluleSabiti (2007) use, is that the definition of a household is quite restrictive. Indeed Russell (2003a, 2003b) has criticised approaches that emphasise current location for not properly understanding the complexity of the social connections between people or how people move between households and locations. Posel, Fairburn, and Lund (2006) point out the importance of such rural-urban linkages in the context of analysing employment and migration behaviours. Hosegood, Benzler, and Solarsh (2005) investigate the meaningfulness of household definitions through detailed qualitative interviews in a rural area in KwaZulu-Natal. They found that "consensus between household respondents about who were members of their household was readily achieved. Households were described in terms of kinship, the recognition of a single head of household, and shared responsibilities and assets" (Hosegood, Benzler, and Solarsh 2005: 51). Nevertheless these household definitions did not always correspond to the de facto definitions employed by surveys and the census, as they frequently included absent household members. This is worth bearing in mind when considering the evidence shown below. Nevertheless, the Agincourt Health and Demographic Surveillance System (HDSS) data that we will be using below does not suffer from these problems, since it employs the more fluid selfdefined concept of a household that Hosegood, Benzler, and Solarsh (2005) found to be robust. The HDSS keeps track of households as the social unit that live and eat together plus the absent members who would eat with them on return. Temporary migration is usually related to employment, job-seeking, or education and is defined as being absent from the rural household for more than six months in the previous year, while still being treated as a household member by those left behind (Kahn et al. 2012). Besides the Agincourt data we also use more traditional surveys. One of these, the National Income Dynamics Survey, also has a somewhat more flexible definition, including members who may or may not be residents. Household members may include 'absent' individuals pro- 
vided they spent 15 days in the last twelve months in the household (Leibbrandt, Woolard, and de Villiers 2009).

We find that the Agincourt information and the more traditional survey data provide similar aggregate pictures for our analyses, so we are confident that the results are not an artefact of a particular definition. Nevertheless one should bear in mind that this will not be true of every measured household outcome (for an example see Posel, Fairburn, and Lund 2006).

Households as defined in this study are both social entities (most often families) and residential units. The residential component is important not only for helping define members of the household (including 'absent' ones) but also because it is key for the delivery of state services such as housing, sanitation, water, and electricity. Since we want to analyse changes in household electricity connections, we will pay considerable attention to the residential component in our approach.

\subsection{Household change and household services in South Africa}

As noted above, a major concern of the literature dealing with households in South Africa has been the question of whether households should be viewed through the lens of the 'nuclear' family or not. Nevertheless against this backdrop the literature has noted some marked changes in the structure of South African households over the postapartheid period, using conventional household definitions. Wittenberg and Collinson (2007: 135) comment on the increase in the number of one-person households in South Africa's national surveys. They describe this as "a veritable explosion in solitary living." They find less compelling evidence of such an increase in rural health and demographic surveillance data. Amoateng, Heaton, and Kalule-Sabiti (2007) also document an increase in the frequency of one-person households nationally, from $16.3 \%$ to $21.2 \%$ between the censuses in 1996 and 2001. Casale, Muller, and Posel (2004) examined labour market trends in South Africa between October 1995 and March 2003, and showed that the average household size in South Africa declined from 3.8 in 1995 to 3.37 in 2003. Hundenborn, Leibbrandt, and Woolard (2016: 5), in a paper exploring the drivers of South African inequality, note that average household size has decreased from 4.38 in 1993 to 3.21 in 2014. Schatz et al. (2015) investigate older adult's living arrangements. They show that the average size of households in which older people resided reduced from 7.1 to 6.7 people per household between 2000 and 2010, and multigenerational structures were increasingly prevalent.

While household size has thus featured in a number of articles, it has not been the major focus of any of these analyses, nor has there been an attempt to investigate the mechanisms through which the reduction in household size has occurred. Nevertheless, understanding this phenomenon is of considerable importance, not least because house- 
holds are the entities against which social well-being is measured. Hundenborn, Leibbrandt, and Woolard (2016) note that household size features in the denominator of per capita household income, so changes in the demographic composition of households has immediate welfare implications.

These connections have not been explored that often. There is a burgeoning literature documenting changes in postapartheid poverty and inequality (Leibbrandt et al. 2010; Leibbrandt, Finn, and Woolard 2012) and living conditions (Bhorat and van der Westhuizen 2013), but much of this literature assumes that households are exogenous. The expansion in access to household services including electricity has also been documented in a number of places (Bekker et al. 2008; Dinkelman 2011). Gaunt (2005: 1310) notes that between 1994 and 2000 around 3 million new electricity connections were made, increasing the proportion of households electrified from about 36\% in 1990 to $67 \%$ in 2000 . The paper tracks how the underlying objectives of electricity provision changed from being economic (during the apartheid era) to being focussed on social concerns, in particular addressing energy poverty, in the postapartheid era. This discussion does not, however, consider how the electrification programme intersects with the processes of household change. Where the household formation rate is mentioned (e.g., in Bekker et al. 2008: 3131, Figure 5) it is treated as a given, exogenous datum.

The main concern of our contribution is methodological - we want to draw attention to the processes of household change and provide some tools for understanding both the reduction in household size and the pattern of gaining or losing electricity access. In particular we want to draw attention to the importance of processes that occur within the locationally bound household unit versus processes that occur as that household dissolves or forms.

\subsection{Measurement of household change}

We begin by using the available cross-sectional survey information to look at householdlevel changes. Obviously this will not permit a truly dynamic analysis. One of the ways the existing literature has tried to incorporate change is by benchmarking the observed trends against aggregate population growth. Kuijsten (1995), for example, decomposes the rate of growth in the number of households into a 'demographic effect' and 'structure effects.' The 'demographic effect' gives the ratio between the actual change in the number of households and the change which would have been expected based on population growth alone. Symbolically,

$$
D E=\frac{H_{t} r_{t, t+1}^{p}}{H_{t+1}-H_{t}} \times 100,
$$


Wittenberg, Collinson \& Harris: Decomposing changes in household measures

where $H_{t}$ is the number of households at time period $t$ and $r_{t, t+1}^{p}$ is the rate of population growth between $t$ and $t+1$ (Kuijsten 1995: 68). The 'structure effects' are defined as

$$
S E_{i}=\frac{H_{i, t+1}-\left[H_{i, t} *\left(1+r_{t, t+1}^{p}\right)\right]}{H_{t+1}-H_{t}} \times 100,
$$

where $H_{i, t}$ is the number of households at time period $t$ in size class $i$. The numerator expresses the difference between the actual change in the number of households in size class $i$ and the hypothetical change if the population growth had occurred in such a way that the distribution of household sizes had stayed fixed. A size class with a positive structure effect has more households in it than would be expected as being due to population increase. This would represent a shift in the distribution towards that size class.

Note that arithmetically $\sum_{i} S E_{i}+D E=100$, i.e., the overall change in the number of households $H_{t+1}-H_{t}$ is fully decomposed into these contributions. It is obvious that if average household size is coming down, this must be due to a shift in the size distribution towards smaller households. The Kuijsten decomposition provides some additional information in that it will show which size classes are growing disproportionately and which are shrinking. Nonetheless it will not show what happens at the two margins that we outlined above: Are the smaller households that we see the remains of large households that have shed some members, or are they newly formed?

There is an additional issue noted by Kerr and Wittenberg (2015) who have suggested that in South Africa's early national household surveys, viz. the October Household Surveys up to and including 1998, small households were undersampled. The instruction to fieldworkers was to interview only one household at each address and, if there was more than one, to select a household with probability proportional to size. Kerr and Wittenberg find no evidence that smaller households were weighted up to compensate for this undersampling. As a result household measures from the early national surveys are likely to be biased. Indeed the sharp drop in household size between 1998 and 2000 evident in Figure 1 is likely to be an artefact of this method. It means that suitable care has to be taken in assessing the trajectory of change. Since we are interested in changes, we will rely mainly on longitudinal data which, in this context, offer a useful check on the reliability of the cross-sections. For the purpose of tracking the impact of household formation and dissolution on the outcomes, longitudinal data is indispensable. We turn now to outline our method for analysing changes in a household outcome measure. 


\section{Decomposing shifts in household outcomes using longitudinal data}

Assume that $y_{i t}$ is our outcome (e.g., size or connection to electricity) for household $i$ in time period $t$, so that $\bar{y}_{t}$ is the average measure for the population in period $t$. We can divide our population (at time $t$ ) into two groups: those households that will turn out to survive to the next period (indicated with a superscript $S$ ) and those that will dissolve at the end of the period (superscript $D$ ). The corresponding average household outcome measures (e.g., household size) for those two subpopulations will be $\bar{y}_{t}^{S}$ and $\bar{y}_{t}^{D}$. In the following period (i.e., $t+1$ ), there will be households that have continued from the previous period (indicated with a superscript $C$ ) and new households (superscript $N$ ). The average outcome measures for those subpopulations can be written as $\bar{y}_{t+1}^{C}$ and $\bar{y}_{t+1}^{N}$.

Figure 3 depicts our classification. Arrows connect the same households between periods. It is important to note that a continuing household in period $t+1$ can be either a 'surviving' or 'dissolving' one with respect to transitions to the following period. This is shown in the Figure by the fact that each household in period $t+1$ has both a $\mathrm{C} / \mathrm{N}$ classification as well as an S/D one. For the moment we are only interested in the transitions from period $t$ to $t+1$. A household that will survive (from the perspective of period $t$ ) has to be a household that has continued (from the perspective of period $t+1$ ), so $\bar{y}_{t+1}^{C}-\bar{y}_{t}^{S}$ is the change in the outcome measured on the same group of households, i.e.,

$$
\bar{y}_{t+1}^{C}-\bar{y}_{t}^{S}=\Delta \bar{y}_{t, t+1}^{S},
$$

where the right hand side should be read as the change in the average value of $y$ measured on the households that will be observed in both $t$ and $t+1$.

Figure 3: Classification of households based on the nature of the transitions between periods

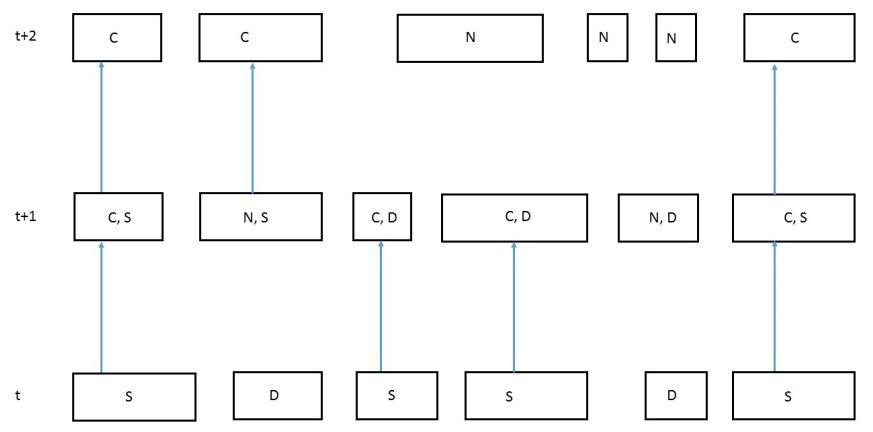

Note: Surviving households $(\mathrm{S})$ at time $t$ (or time $t+1$ ) will be seen in the following period, where they will be classified as continuing (C). They are connected by arrows. Households that don't survive are labelled as dissolving (D). New households at time $t+1$ or $t+2$ are labelled ' $N$.' 
Wittenberg, Collinson \& Harris: Decomposing changes in household measures

The overall population averages in period $t$ and $t+1$ can be written as weighted averages of the outcomes in their relevant subpopulations; i.e., we have

$$
\begin{aligned}
\bar{y}_{t} & =\left(1-\theta_{t}\right) \bar{y}_{t}^{D}+\theta_{t} \bar{y}_{t}^{S} \\
\bar{y}_{t+1} & =\left(1-\phi_{t+1}\right) \bar{y}_{t+1}^{N}+\phi_{t+1} \bar{y}_{t+1}^{C},
\end{aligned}
$$

where $\theta_{t}$ is the proportion of households in period $t$ that will survive to period $t+1$ and $\phi_{t+1}$ is the proportion of households in the population at time $t+1$ that have survived from the previous period. In our diagram $\theta_{t}$ is $\frac{2}{3}$ (four $\mathrm{S}$ households and two $\mathrm{D}$ ones), while $\phi_{t+1}$ is also $\frac{2}{3}$ (four $\mathrm{C}$ households and two $\mathrm{N}$ ones). So

$$
\Delta \bar{y}_{t+1}=\theta_{t} \Delta \bar{y}_{t, t+1}^{S}+\left(1-\theta_{t}\right)\left(\bar{y}_{t+1}^{N}-\bar{y}_{t}^{D}\right)+\left(\theta_{t}-\phi_{t+1}\right)\left(\bar{y}_{t+1}^{N}-\bar{y}_{t+1}^{C}\right) .
$$

This decomposition is not unique. We could as easily have written

$$
\Delta \bar{y}_{t+1}=\phi_{t+1} \Delta \bar{y}_{t, t+1}^{S}+\left(1-\phi_{t+1}\right)\left(\bar{y}_{t+1}^{N}-\bar{y}_{t}^{D}\right)+\left(\theta_{t}-\phi_{t+1}\right)\left(\bar{y}_{t}^{D}-\bar{y}_{t}^{S}\right) .
$$

Unless there is a very rapid increase or decline in the number of households $\theta_{t}-\phi_{t+1}$ should be small and the two decompositions should give similar results. In the empirical results we report the first decomposition. The second provides qualitatively similar results and is available on request from the authors.

We term the three effects:

- The 'within household change' effect $\theta_{t} \Delta \bar{y}_{t, t+1}^{S}$

- The 'replacement' effect $\left(1-\theta_{t}\right)\left(\bar{y}_{t+1}^{N}-\bar{y}_{t}^{D}\right)$, since the difference $\bar{y}_{t+1}^{N}-\bar{y}_{t}^{D}$ represents the effects of new households replacing those going out of existence

- The 'dilution' effect $\left(\theta_{t}-\phi_{t+1}\right)\left(\bar{y}_{t+1}^{N}-\bar{y}_{t+1}^{C}\right)$, since $\theta_{t}-\phi_{t+1}$ is nonzero only if there is a net change in the number of households and the term $\bar{y}_{t+1}^{N}-\bar{y}_{t+1}^{C}$ reflects how newly formed households differ from surviving ones. In a period of rapid household formation, the continuing (surviving) households become a decreasing fraction of the entire population of households. Their contribution to the overall mean household size therefore becomes diluted by the new households.

\section{Data}

\subsection{Data requirements}

A key requirement in order to implement this technique is an ability to identify households that are the same in two time periods, so that we can measure $\Delta \bar{y}_{t, t+1}^{S}$. We also need to be able to identify households that will cease to exist in the next period as well 
as households that are newly formed in any given period. Finally we need to be able to estimate $\theta_{t}$ and $\phi_{t+1}$, the population proportions of households that will survive and households that have continued, respectively.

Cross-sectional data will not allow us to estimate any of these quantities. However, demographic surveillance data and certain types of household panels will allow us to estimate all of these. We will discuss in turn these two types of data and the specific South African datasets that we will use.

\subsection{Demographic surveillance data}

Demographic surveillance sites have been set up in many countries in the world. The INDEPTH network (http://www.indepth-network.org) acts as umbrella organisation for many of them. Central to the operation of these sites is the monitoring of demographic events on a closed population on an ongoing basis. These sites therefore are well positioned to track household formation and dissolution processes as well as the population proportions required for the decomposition. Many of these sites measure a range of household outcomes besides standard demographic variables for which the decomposition would be suitable.

\subsubsection{The Agincourt site}

The MRC/Wits Agincourt Unit was established in 1992 with the aim of addressing issues around the decentralisation of health services and to provide accurate information for planning (Tollman 1999; Tollman et al. 1999). The strategy was to conduct health and demographic surveillance, underpinning a programme of interdisciplinary health and population research. The Agincourt subdistrict was selected in part because it reflects many of the key developmental challenges. It is a subdistrict of the Bushbuckridge region of Limpopo Province (see Figure 4). In the 1990s the area lacked a functioning vital registration system, thus making ongoing demographic surveillance appropriate for evaluating government's efforts in improving this system. Furthermore, the area formed part of the previous Gazankulu homeland and therefore exhibits many of the characteristics of these areas: a lack of infrastructure and a population that has been subject to forced removals, betterment planning, and the imposition of a labour migration system (for a discussion of some of these processes see Niehaus 2001). 
Figure 4: The original Agincourt field site covers 21 villages in the Bushbuckridge area

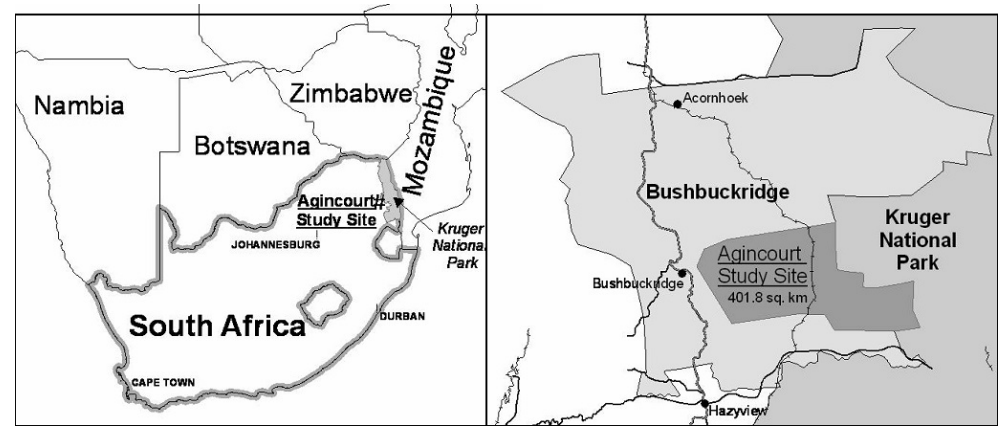

\subsubsection{The Health and Demographic Surveillance System (HDSS)}

The Agincourt HDSS monitors key demographic events and socioeconomic variables in the Agincourt sub-district. A baseline census was conducted in 1992 and since 1999 there have been annual census rounds (Kahn et al. 2012). The main demographic, health, and socioeconomic variables measured routinely by the HDSS include births, deaths, inand out-migrations, household relationships, resident status, refugee status, education, and antenatal and delivery health-seeking practices (Tollman 1999; Tollman et al. 1999; Collinson et al. 2002). Temporary migrants are accounted for by including on the household roster nonresident members who retain significant contact and links with the rural home (Collinson et al. 2001). The 'share common pot' definition of a household is thus expanded to include the temporary migrants who would normally share the same pot on return. The definition of household head is the main household decision maker, as reported by the household respondent. There have been several 'add-on' modules that have been run. For example every second year since 2000 there has been a household asset module which includes information on household access to services, e.g., electricity.

In the update rounds a trained lay fieldworker interviews the most competent respondent available at the time of visit. Individual information is checked for every household member. All events that have occurred since the previous census are recorded. Where possible, questions are directed to particular household members; for example, maternity history or pregnancy outcome information is asked directly from the woman involved, and a verbal autopsy is conducted with the person most closely involved with the deceased during the terminal illness. Revisits are undertaken when appropriate respondents are not available. Data quality checks include duplicate visits on $2 \%$ of households. In addition a number of validation checks are built into the fieldwork and data entry programme. 
The software system used consists of a relational database constructed in Microsoft SQL Server.

\subsubsection{Tracking households over time}

One of the key questions for our empirical analysis is to identify the 'same' household at different time periods. The HDSS keeps track of dwelling units, households (linked to a 'household head' and to a dwelling), and individuals. For our purposes we have used the HDSS information to identify continuing households by:

- Dwelling: continuing residence in the same location

- Overlapping membership: there must be at least one individual from the previous household still living in the dwelling.

One of the implications of this definition is that if a family group moves from one dwelling to another (as a group) this will be classified as a household dissolution event followed by a household formation one. This definition was adopted partially for convenience. Firstly, it corresponds to how the HDSS keeps track of households. Secondly, many of the moves of entire families are migrations out of the HDSS area. If we were to adopt a definition of the household that did not have a locational component, we would not know how to treat them in our analysis, since we don't know what happened to them (they would be lost due to attrition). With our definition we do not need to know what happened to them because once the household has 'dissolved' it no longer features in any analyses.

While the locational definition is convenient, it also makes sense for our application. If one thinks about household services (provision of water, electricity), these are locationspecific and it is useful to differentiate changes in access to a service for a given group of people at a location (a 'household') from changes induced by those people migrating to a different location.

\subsection{Household panels}

Nationally representative household panels are in existence in many countries and have become key instruments for measuring social changes (Rose 1995). Many of these panels originate at the baseline from a nationally representative survey of households. For instance at the inception the target population of the European Community Household Panel (ECHP) consisted "of all private households throughout the national territory of each country" (Peracchi 2002: 65). The members of those households become the core panel members. In subsequent periods those individuals are tracked. In this way these household panels become panels of individuals. 
However, in subsequent waves information on the households in which those individuals find themselves is also often recorded, leading in the case of the ECHP to a distinction between "sample and nonsample persons" (Peracchi 2002: 66). It is therefore possible, at least in principle, to classify households as surviving/newly formed/dissolving and to get estimates of household formation and dissolution rates. Harris (2016) has discussed how this can be done for the South African household panel, the National Income Dynamics Study.

\subsubsection{The National Income Dynamics Study (NIDS)}

South Africa's National Income Dynamics Study (NIDS) was modelled on other household panels, such as the Panel Study of Income Dynamics in the United States (for more details see Leibbrandt, Woolard, and de Villiers 2009). It was commissioned by South Africa's Presidency in an effort to track long-run poverty and well-being. The Southern Africa Labour and Development Research Unit (SALDRU) at the University of Cape Town won the bid and ran the baseline study in 2008. Since then it has administered three other waves, around one round every second year. The core concerns of the study are incomes, expenditures, labour market participation, education, health (including anthropometrics), and household well-being (e.g., access to services).

At the baseline the sample was designed to be nationally representative. It was a two-stage sampling design with 400 primary sampling units (PSUs) extracted from Statistics South Africa's 2003 master sample and a target of 24 households per PSU. The final realised sample was around 7,300 households and about 28,000 individuals Leibbrandt, Woolard, and de Villiers (2009). These individuals became the 'Continuing Sample Members' (CSMs) for the subsequent waves. Babies born to CSM women also became CSMs. At each of the subsequent waves, individuals who were coresident with CSMs were also interviewed. These individuals were classified as 'Temporary Sample Members' (TSMs).

\subsubsection{Tracking households in NIDS}

In order to implement our decomposition, we need to identify continuing households as well as newly formed and dissolving ones. We use the same decision rule as in the case of the Agincourt HDSS data; i.e., a household will be deemed to be the same if:

- it remains resident in the same location

- there is an overlap of membership from one period (wave) to the next.

Choosing the same definition of household continuity makes sense given that we want to compare results from NIDS to those from the Agincourt HDSS. It also makes 
sense given our application to household services. But making location central to the definition of the household is less self-evident in the case of NIDS than it is for the Agincourt HDSS, particularly since moves are tracked across South Africa. This raises the question whether choosing a different definition of a continuing household would change the results that we show below. For instance, we could define the 'same' household in two waves of NIDS by a 'majority' criterion - the successor household is that residential unit which contains more than $50 \%$ of the members of the current household, regardless of location. In the online appendix to this article, we outline this approach in more detail and show that it doesn't affect the conclusions reached with the current definition. Different definitions have different types of attrition and missing value problems. For instance with any of the definitions that we are using, we face a difficulty, if a single individual leaves one particular dwelling and is tracked to another one. We need to decide whether to identify that household as a newly formed one, or whether it should be thought of as an individual joining a pre-existing household. This is of some importance, since preexisting households (i.e., households that could have been sampled at baseline but were not) should not be included in the statistics when calculating wave-on-wave changes.

In order to differentiate between these for the case of our location-based definition, we use information on whether the TSMs in the household in question have also moved. If everyone has moved then it qualifies as a new household.

An additional problem is that if individuals are lost to the panel (i.e., the problem of attrition), we may also lose information about the fate of the households in which they reside; i.e., we may not know whether a particular household dissolved or continued (and if it continued what happened to the household outcome that we are interested in). This is potentially serious since household attrition is the most prevalent form of attrition in NIDS (Brown et al. 2012: 23). Around 16\% of individuals could not be tracked from wave 1 to wave 2 because the entire household was lost from the sample - in most cases due to the fact that the household moved and could not be traced at the forwarded address. Another $2 \%$ attrited due to refusal to participate in the follow-up. As a result all analyses using NIDS (including cross-sectional ones) need to bear this in mind. In our analyses we see the same patterns in cross-sectional datasets which are not subject to attrition, and our longitudinal findings parallel those from Agincourt, which is not subject to this problem, so we are confident that our results are not an artefact of the missing data. Nevertheless, we still need to account for the attrition problem. There are at least three ways in which one might do this:

- reweight the observed observations for the ones lost to attrition

- impute outcomes to the attrited units

- bound the range of outcomes by assuming maximum or minimum values for the attrited units.

In this study, we have imputed whether unobserved households continue to exist or 
Wittenberg, Collinson \& Harris: Decomposing changes in household measures

not (or whether the associated CSMs form new households), and have reweighted the observed units to account for any conditional attrition.

\section{Methods}

\subsection{Changes in household size}

We will investigate the usefulness of our decomposition technique in analysing the observed reduction in household size by three methods: Firstly, we will use the simple cross-sectional evidence to track the changes over time. We will do so by using the crosssectional components of both the Agincourt HDSS and the NIDS datasets, as well as the more standard nationally representative surveys run by Statistics South Africa: the October Household Surveys, Labour Force Surveys, and Quarterly Labour Force Surveys. We will use the harmonised series of these datasets released as PALMS - postapartheid Labour Market Series (Kerr, Lam, and Wittenberg 2013). As noted by Kerr and Wittenberg (2015), however, the early household surveys provide biased evidence due to the undersampling of small households. Consequently we try to correct for that by weighting up the small households as discussed by Machemedze, Kerr, and Wittenberg (2014). We compare the cross-sectional evidence from the national surveys to the equivalent crosssectional pictures from the Agincourt HDSS data, and the NIDS data.

Secondly, we implement the Kuijsten decomposition technique given by equations 1 and 2 on all of the cross-sections available to us, viz. the Statistics SA household surveys as embodied in PALMS, the Agincourt HDSS, and NIDS.

Finally we implement our decomposition on the longitudinal data available in the Agincourt HDSS and NIDS.

\subsection{Electricity connections}

In the case of access to electricity we will also approach the topic incrementally, first using the available cross-sections to describe the changes, using the same type of survey evidence that we use in tracking household size, except that we make use of the General Household Surveys instead of the Labour Force Surveys.

We can provide a snapshot of how the roll-out of services proceeds by noting that the change in the count of unserviced households can be written as

$$
\underbrace{H_{0, t}}_{\text {unserviced HH at } t}+\underbrace{\left(H_{t+1}-H_{t}\right)}_{\text {net new households }}-\underbrace{\left(H_{1, t+1}-H_{1, t}\right)}_{\text {net new connections }}=\underbrace{H_{0, t+1}}_{\text {unserviced HH at } t+1}
$$


where $H_{1, t}$ and $H_{0, t}$ refer to households with and without services respectively. By dividing this identity by $H_{t}$ we can express this in terms of rates

$$
b_{t}+r_{t, t+1}^{H H}-n_{t, t+1}=b_{t+1}^{*},
$$

where $b_{t}$ is the backlog in period $t, r_{t, t+1}^{H H}$ is the household growth rate between $t$ and $t+1, n_{t, t+1}$ is the rate of new service connections and $b_{t+1}^{*}$ is the backlog in period

$t+1$ expressed as proportion of $H_{t}$ rather than $H_{t+1}$. Of course $b_{t+1}=b_{t+1}^{*} \frac{H_{t}}{H_{t+1}}=$ $b_{t+1}^{*} /\left(1+r_{t, t+1}^{H H}\right)$, so it is easy to calculate $b_{t+1}$ given $b_{t}, r_{t, t+1}^{H H}$ and $n_{t, t+1}$. Equation 5 is useful because it expresses directly the implementation challenge facing government: the race between household formation and service roll-out and the impact this has on the evolution of the backlog.

In the final part of our analyses we implement the decomposition we outlined in section 3 on electricity connections in the Agincourt HDSS and NIDS longitudinal datasets.

\section{Results}

\subsection{Changes in household size}

In Figure 1 we show the reduction in household size according to different cross-sectional surveys. The solid line represents the evolution according to the October Household Surveys (OHSs), Labour Force Surveys (LFSs), and Quarterly Labour Force Surveys (QLFSs). The pattern suggests a major collapse in household size concentrated in the period 1998 to 2000. Given the undersampling of small households in the early October Household Surveys, as discussed by Kerr and Wittenberg (2015), this picture should be treated with some caution. The dashed line labelled 'recalibrated' shows the pattern if small households are weighted upwards in this period, as proposed by Machemedze, Kerr, and Wittenberg (2014). After 2008 we can compare the average household size as reflected in the Quarterly Labour Force Survey with the numbers as emerging from the National Income Dynamics Study. Unlike the cross-sectional surveys run by Statistics South Africa, NIDS does allow also for a looser definition of the household. The names of 'nonresident' household members are recorded. These are individuals (largely migrant workers) who still have an affiliation with the household but spend less than the requisite time (i.e., four days a week) in the household to be counted as a 'resident' member. The dotted line in Figure 1 indicates the pattern of household size if this broader definition of household size is adopted, whereas the dashed line represents the more restrictive count based only on resident members. Interestingly enough these two estimates bound the results obtained from the QLFSs. Both of the NIDS estimates show a noticeable reduction 
in average household size between 2008 and 2012, although the more restrictive definition shows an uptick in 2010.

The effect of a less restrictive definition on the measurement of household size is also evident in the case of Agincourt, which also keeps migrant members on the household roster lists. Figure 5 presents the initial Agincourt picture. This is given by the solid line which shows a very smooth reduction of average household size over the period as a whole. This trend is juxtaposed with the 'rural' samples from the national surveys. From 2004 to 2008 there was no 'rural' indicator released with the LFSs, so there is a break in the overall trajectory in Figure 5. Nevertheless, it is evident that rural household size has also come down. The NIDS pattern is a bit more complicated, but it also suggests that over the period as a whole households became smaller.

Figure 5: Comparing average household size in the Agincourt area to the average for all rural areas in the country, according to nationally representative household surveys

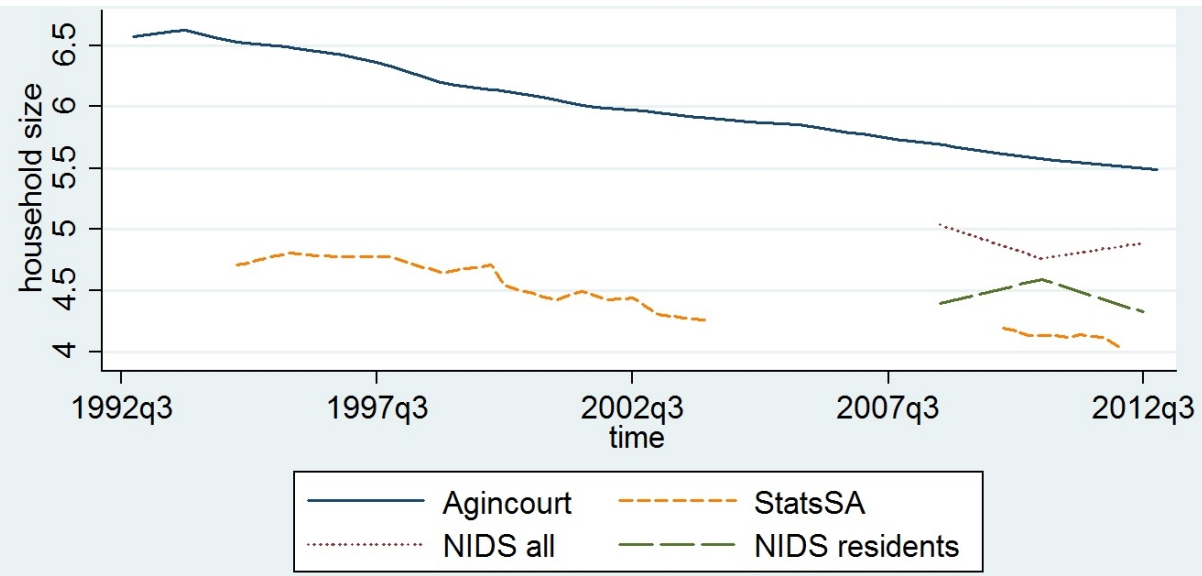

Note: Own calculations from the following sources: Agincourt - Agincourt HDSS data. Stats SA - rural samples of October Household Surveys, Labour Force Surveys and Quarterly Labour Force Surveys, weights recalibrated for undersampling. NIDS all - rural sample from National Income Dynamics Study, all members. NIDS residents - as for NIDS, resident members only.

Several points stand out in the Figure: Firstly average household size in Agincourt is bigger than in other rural households as measured in the national surveys, even when compared to the looser definition used in NIDS. There are two likely reasons for this: Even the looser definition in NIDS requires a person to have spent 15 days in the previous year in the household, whereas in the case of Agincourt people are kept on the roster if the household expects the migrants to return. Also the category of 'rural' in the national 
surveys includes some contexts which may better be thought of as periurban, whereas Agincourt is a 'deep rural' community.

Secondly the NIDS point estimates for 2010 seem somewhat odd: the gap between the looser and more restrictive definitions is much smaller in this period than in either 2008 or 2012. This suggests that the weighting corrections may not have properly corrected for selective attrition of certain types of households. This point is worth bearing in mind when assessing the decompositions below, in particular when analysing the changes from wave 1 to wave 2 .

Thirdly, despite the differences in definitions and measurement, the magnitude of the reduction in household size over the period 1994 to 2012 is similar: around one person from an initial household size of 6.5 in the case of Agincourt and 0.7 from an initial household size of 4.7 in the case of the national surveys. Both amount to a $15 \%$ reduction.

\section{Table 1: Change in the distribution of households}

\begin{tabular}{|c|c|c|c|c|}
\hline & $\begin{array}{l}\text { Agincourt } \\
1994-2012\end{array}$ & $\begin{array}{l}\text { PALMS } \\
\text { recalibrated } \\
1994-2012\end{array}$ & $\begin{array}{l}\text { PALMS } \\
\text { original wts } \\
1994-2012\end{array}$ & $\begin{array}{l}\text { NIDS } \\
2008-2012\end{array}$ \\
\hline Population growth rate (\%) & 22.1 & 26.0 & 26.0 & 5.5 \\
\hline Annual population growth (\%) & 1.1 & 1.3 & 1.3 & 1.3 \\
\hline Household growth rate (\%) & 45.1 & 51.0 & 59.2 & 9.9 \\
\hline Annual household growth (\%) & 2.1 & 2.3 & 2.6 & 2.4 \\
\hline Demographic effect & 49.0 & 50.9 & 43.9 & 55.5 \\
\hline \multicolumn{5}{|l|}{ Structure effects } \\
\hline 1-person households & 11.1 & 31.0 & 40.0 & 83.4 \\
\hline 2-person households & 10.1 & 13.9 & 18.0 & -15.7 \\
\hline 3-person households & 16.3 & 13.3 & 10.0 & -17.1 \\
\hline 4-person households & 16.3 & 8.0 & 5.2 & -17.2 \\
\hline 5-person households & 10.4 & -1.2 & -2.1 & 1.2 \\
\hline 6-person households & 5.4 & -3.1 & -3.2 & 2.9 \\
\hline 7-person households & -1.1 & -4.5 & -4.2 & 3.3 \\
\hline 8-person households & 0.0 & -2.9 & -2.7 & 1.1 \\
\hline 9-person households & -3.6 & -2.0 & -1.8 & 4.6 \\
\hline 10-person households & -3.2 & -3.6 & -3.4 & -0.2 \\
\hline 11-person households & -2.4 & 0.4 & 0.4 & -1.5 \\
\hline 12-person households & -1.7 & 0.1 & 0.1 & 2.1 \\
\hline 13-person households & -1.1 & 0.0 & 0.0 & -1.2 \\
\hline 14-person households & -0.5 & 0.0 & 0.0 & 0.5 \\
\hline 15+-person households & -4.7 & -0.1 & -0.1 & -1.7 \\
\hline
\end{tabular}

In Table 1 we provide some aggregate statistics for the different datasets for the period as a whole, as well as implementing the Kuijsten decomposition. According to all three sources the population growth rate is a shade over $1 \%$ per annum. Also, all data sources agree that the rate of household formation was considerably higher than the pop- 
Wittenberg, Collinson \& Harris: Decomposing changes in household measures

ulation growth rate: ranging from an average of $2.1 \%$ per annum in the case of Agincourt to $2.6 \%$ per annum if the Statistics SA datasets are used with the unadjusted weights. As we argued earlier, there is good evidence to suggest that the early OHSs undersampled small households and as a result underestimated the total number of households. The recalibrated estimates suggest a growth rate of $2.3 \%$ for the number of households.

Table 2: Decomposing change in household size

\begin{tabular}{lrrrr}
\hline $\begin{array}{l}\text { Panel A: } \\
\text { Agincourt }\end{array}$ & $\begin{array}{l}\text { overall } \\
\text { change }\end{array}$ & within & replace & dilute \\
\hline $1994-1995$ & -0.036 & 0.0456 & -0.0309 & -0.0507 \\
$1995-1996$ & -0.059 & -0.0054 & -0.0271 & -0.0267 \\
$1996-1997$ & -0.093 & 0.0394 & -0.0717 & -0.0603 \\
$1997-1998$ & -0.141 & 0.0000 & -0.1170 & -0.0242 \\
$1998-1999$ & -0.050 & 0.0595 & -0.0096 & -0.1003 \\
$1999-2000$ & -0.067 & 0.0207 & -0.0461 & -0.0421 \\
$2000-2001$ & -0.081 & -0.0232 & -0.0069 & -0.0511 \\
$2001-2002$ & -0.032 & -0.0125 & -0.0026 & -0.0172 \\
$2002-2003$ & -0.046 & -0.0238 & 0.0043 & -0.0263 \\
$2003-2004$ & -0.042 & -0.0194 & 0.0087 & -0.0310 \\
$2004-2005$ & -0.022 & 0.0026 & 0.0036 & -0.0280 \\
$2005-2006$ & -0.064 & -0.0145 & 0.0066 & -0.0558 \\
$2006-2007$ & -0.060 & -0.0297 & 0.0172 & -0.0479 \\
$2007-2008$ & -0.056 & -0.0085 & 0.0105 & -0.0582 \\
$2008-2009$ & -0.062 & -0.0199 & 0.0213 & -0.0637 \\
$2009-2010$ & -0.047 & -0.0004 & 0.0087 & -0.0552 \\
$2010-2011$ & -0.044 & 0.0101 & 0.0072 & -0.0618 \\
$2011-2012$ & -0.032 & 0.0144 & 0.0033 & -0.0497 \\
\hline $1994-2012$ & -1.034 & 0.0350 & -0.2205 & -0.8502 \\
\hline Panel B: & overall & & & \\
NDIS & change & within & replace & dilute \\
\hline 2008-2010 & 0.111 & 0.236 & -0.064 & -0.062 \\
$2010-2012$ & -0.248 & -0.032 & -0.113 & -0.140 \\
\hline $2008-2012$ & -0.137 & 0.204 & -0.177 & -0.202 \\
\hline & & & & \\
\hline
\end{tabular}

The population growth rate can therefore explain only about a half of the overall increase in the number of households, as shown by the 'demographic effects.' Examining the 'structure effects,' it is clear that the growth rate in the smaller households (particularly one-person households) vastly outstripped the population growth rate, while the number of larger households lagged behind it, leading to negative structure effects. The NIDS panel is a significant exception to this pattern, with two-, three-, and four-person households all showing significantly negative structure effects. This suggests that there may have been an attrition problem, with certain smaller types of households not being tracked well over time. Curiously this did not apply to one-person households which one 
might have expected to have been particularly hard to track. With the exception of the NIDS results, the structure effects suggest a clear shift in the distribution of household types from bigger to smaller households. On its own, however, this does not indicate what happened 'within' households.

The results from our decomposition are given in Table 2. The decomposition for the Agincourt demographic data is given in the top panel. It indicates that over the period 1994 to 2012 households shed (on average) one member. Interestingly, however, none of this happened 'within' continuing households. If anything, continuing households grew a tiny amount $(0.035)$. Around $21 \%$ of the reduction is accounted for by the fact that newly formed households were smaller than dissolving households. The balance is due to the dilution effect - the fact that there were so many new households, significantly smaller than the continuing ones, that they managed to bring down the overall average household size by 0.85 persons over this period. It is clear that these new households on the whole did not emerge as 'break-aways' from existing households, since there is no evidence that these became smaller. Instead it seems that household dissolution (in this context often migration events) are key episodes leading to the reconstitution of households.

The NIDS panel covers a much shorter time period, but it provides the same takehome message. We see (in Panel B of Table 2) that the 'replacement' and 'dilution' effects are again strongly negative. In this case, however, they are somewhat offset by growth within continuing households between wave 1 and wave 2 . It again seems clear that household dissolution, reconstitution, and rapid new household formation are the key drivers of the observed decrease in household size.

\subsection{Changes in household energy connections}

The aggregate rates of household energy connections for South Africa are shown in Figure 2. The Agincourt data is shown in Figure 6. This does not show any marked decrease in the average connection rate around 2008, but it does show a slight dip between 2005 and 2007. 
Figure 6: Penetration of household electricity use in the Agincourt area according to two measures: household electricity uses for lighting and cooking

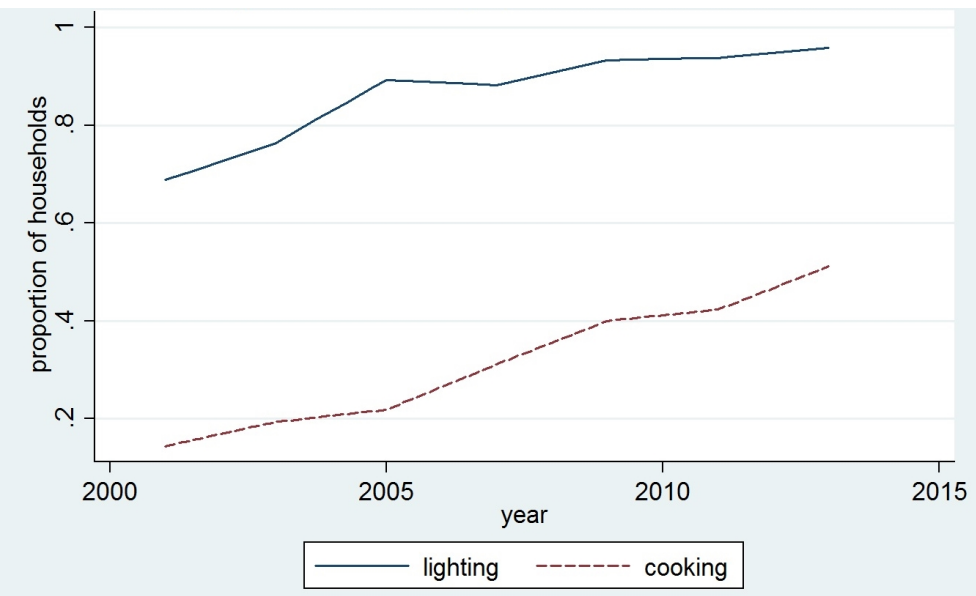

Table 3 provides evidence how important the interplay between household dynamics and connection rates are. We see in the top part of the panel that over the 18-year period covered by the General Household Surveys and October Household Surveys, the number of households using electricity for lighting increased around $160 \%$. This translates into an annual increase in connections of more than 5\%. The Agincourt data on infrastructure is for a shorter time period, but over the ten years between 2001 and 2011 additional connections also increased at more than 5\% per annum. These rates of increase are in line with the rapid electrification documented by Gaunt (2005).

Table 3: $\quad$ Change in the availability of electricity

\begin{tabular}{|c|c|c|c|c|}
\hline & $\begin{array}{l}\text { Agincourt } \\
1994-2012\end{array}$ & $\begin{array}{l}\text { OHS/GHS } \\
\text { recalibrated } \\
1994-2012\end{array}$ & $\begin{array}{l}\text { OHS/GHS } \\
\text { original } \\
1994-2012\end{array}$ & $\begin{array}{l}\text { NIDS } \\
2008-2012\end{array}$ \\
\hline Growth in connections (\%) & 72.2 & 156.9 & 169.3 & 17.3 \\
\hline Annual growth rate in connections (\%) & 5.58 & 5.38 & 5.66 & 4.07 \\
\hline Population growth (\%) & 12.21 & 23.79 & 23.50 & 5.48 \\
\hline \multicolumn{5}{|l|}{ Change in backlog } \\
\hline Backlog at start (\%) & 31.21 & 47.68 & 46.92 & 18.21 \\
\hline Household formation rate (\%) & 26.33 & 54.71 & 64.58 & 9.86 \\
\hline New connection rate (\%) & -49.65 & -82.07 & -89.88 & -14.16 \\
\hline Backlog at end (\%) & 6.24 & 13.13 & 13.13 & 12.67 \\
\hline
\end{tabular}


This rapid rate of service roll-out, however, occurred against a backdrop of rapid household formation, as we noted in the previous section. Compared to the baseline backlog of $31 \%$ of households in the Agincourt area in 2001 the new connection rate of $50 \%$ would have more than wiped out the backlog, if it hadn't been for the fact that new household formation added $26 \%$ on to the baseline. Nevertheless, the roll-out was sufficiently strong that it brought the overall backlog down to $6 \%$ at the end of the period.

The same pattern can be seen in the case of the national data for the period 1994 to 2012. We see that whether or not we recalibrate the OHSs to take account of the deficit of small households, the new connection rate would have entirely eliminated the national backlog if it hadn't been for new households being formed. The only period in which this does not seem to have been the case is the period since 2008, as measured by the National Income Dynamics Study. Nevertheless, even in this case new connections outstripped new households thus ensuring that the overall backlog came down.

Table 3 also provides the population growth rate over the period covered by the data. If household formation had been at this lower rate, then a simple counterfactual calculation suggests that the new connection rate would have been sufficient to eliminate the entire backlog in the case of both Agincourt and the country as a whole for the period 1994 to 2012.

The cross-sectional picture therefore strongly points to the importance of the connection between net household formation dynamics and the evolution of the proportion of households with services. Table 4 shows how these dynamics play themselves out on the 'intensive' and 'extensive' margin, in terms of our households' decompositions.

\section{Table 4: Decomposing change in electricity availability}

\begin{tabular}{|c|c|c|c|c|}
\hline $\begin{array}{l}\text { Panel A: } \\
\text { Agincourt }\end{array}$ & $\begin{array}{l}\text { overall } \\
\text { change }\end{array}$ & within & replace & dilute \\
\hline $2001-2003$ & 0.075 & 0.0782 & 0.0087 & -0.0119 \\
\hline $2003-2005$ & 0.130 & 0.1220 & 0.0063 & 0.0015 \\
\hline $2005-2007$ & -0.011 & -0.0036 & 0.0022 & -0.0096 \\
\hline $2007-2009$ & 0.051 & 0.0633 & 0.0019 & -0.0146 \\
\hline 2009-2011 & 0.005 & 0.0086 & -0.0128 & 0.0094 \\
\hline 2001-2011 & 0.250 & 0.2686 & 0.0063 & -0.0252 \\
\hline $\begin{array}{l}\text { Panel B: } \\
\text { NDIS }\end{array}$ & $\begin{array}{l}\text { overall } \\
\text { change }\end{array}$ & within & replace & dilute \\
\hline 2008-2010 & -0.020 & 0.009 & -0.011 & -0.001 \\
\hline 2010-2012 & 0.077 & 0.058 & 0.019 & 0.002 \\
\hline 2008-2012 & 0.057 & 0.049 & 0.008 & 0.001 \\
\hline
\end{tabular}


The pattern for Agincourt, shown at the top of the table, is clear-cut. The 25percentage-point increase in services (and an equivalent drop in the backlog) occurred entirely 'within' households; i.e., households did not improve their access by moving to a serviced location, but received new connections at their current location. Indeed the 'dilution' effect is negative, suggesting that newly formed households had less access than continuing households. In fact the difference $\bar{y}_{t+1}^{N}-\bar{y}_{t+1}^{C}$ is 0.189 when averaged across the five data points. This suggests that families move to locations that are initially unserviced, but that over time acquire services. The fact that the 'replacement' effect is weakly positive suggests that households that dissolve/migrate had even worse access than the newly formed households.

The pattern in the NIDS dataset is more complicated. The 2008 to 2010 changes suggest that the drop in access (shown in Figure 2) is mainly driven by loss of access within continuing households, but that dissolving households also had better access than new ones (leading to a negative 'replacement' effect). This is an interesting observation since it raises the possibility that in some instances roll-out of services has occurred in areas which may lose population in subsequent periods. Interestingly enough the Agincourt area also showed a negative replacement effect in this period (2009-2011). This possibility is important for policy purposes, since it means that planning of electrification, as discussed, for instance by Bekker et al. (2008) needs to be aware of not only the rate at which household growth is likely to outstrip population growth, but also migration patterns.

In the case of NIDS, the transitions from 2010 to 2012 show reversals in the signs of both of these effects. In neither period does dilution seem to change aggregate connection rates much.

The negative 'within' effects in NIDS 2008-2010 and in Agincourt 2005-2007 are of some interest because they indicate that the net increase in connections shown in the aggregate statistics in Table 3 may actually conceal some disconnections. Harris (2016) has investigated these in the NIDS data in more detail. What was driving these is a topic for future research.

The broad-brush picture revealed by our decomposition is consistent with the simple 'race' between services rolled out to existing households and the setting up of new unserviced households. Nevertheless, this picture is complicated by the fact that disconnections in some periods seemed to outweigh new connections, at least for continuing households. Furthermore the negative 'replacement' effects in NIDS 2008-2010 and in Agincourt 2009-2011 suggests that in some cases services have been rolled out to areas which end up losing households to outmigration. 


\section{Conclusion: Households and social dynamics}

The central concern of the paper has been to reflect on some of the big changes that have occurred in the nature of households and in the access to household services over the postapartheid period. The statistics shown in table 1 show a very rapid rate of household formation and a shift towards smaller households. In table 3 we have shown that the rollout of electricity has been even more rapid than net household formation. These rates are truly impressive and provide the background for any research that is trying to understand how this occurred.

We argue that any analysis of households and household services has to grapple with the fact that households are not fixed entities, as much of the existing literature has assumed, but are subject to recomposition, dissolution, and re-formation. Changes happen both 'within' households and at the dissolution/formation margin. Our decomposition draws specific attention to these. In the case of changes in household size we showed that much of the change seems to occur at the point where people leave one location and then set up at another. In a few cases these dissolution/formation processes also have implications for service access. More commonly, however, the rapid process of household formation sets up a 'race' in which the roll-out of services is continually trying to play catch-up with newly set up less-serviced households. Our decompositions manage to draw attention to these processes. Our decompositions have also revealed that the service roll-out is not always a linear process: Disconnections seem to occur also and in some cases households seem to leave dwellings with services in favour of locations without them. This has not been noted hitherto.

Even so, our decomposition relies on averages which smooth over new connections and disconnections. It is therefore not the last word on the full complexity of household changes. For that other tools will be necessary, e.g., some of the more conventional panel techniques. Nevertheless, even in those cases it is worth taking note of the fact that many interesting changes happen not within the panel, but at the point at which entities exit and enter.

\section{Acknowledgements}

This work is based on research supported by South Africa's National Research Foundation (ESRC-NRF International Centre Partnership, Ref. ICPC150423117553). Any opinion, finding, conclusion, or recommendation expressed in this material is that of the authors, and the NRF does not accept any liability in this regard. Additional funding is acknowledged from the University of Cape Town, the University of the Witwatersrand, the South African Medical Research Council, the Wellcome Trust (Grants 058893/Z/99/A; 069683/Z/02/Z; 085477/Z/08/Z), the William and Flora Hewlett Foundation, the National 
Wittenberg, Collinson \& Harris: Decomposing changes in household measures

Institute on Aging (NIA) of the NIH, and the Andrew W. Mellon Foundation. We would like to thank the Medical Research Council/University of the Witwatersrand Rural Public Health and Health Transitions Research Unit (Agincourt) for their unstinting support over many years and for making their data available. 


\section{References}

Amoateng, A. (2007). Towards a conceptual framework for families and households. In: Amoateng, A. and Heaton, T. (eds.). Families and households in post-apartheid South Africa: Socio-demographic perspectives. Cape Town: HSRC Press: 27-42.

Amoateng, A. and Heaton, T. (2007). Families and households in post-apartheid South Africa: Socio-demographic perspectives. Cape Town: HSRC Press.

Amoateng, A., Heaton, T., and Kalule-Sabiti, I. (2007). Living arrangements in South Africa. In: Amoateng, A. and Heaton, T. (eds.). Families and households in postapartheid South Africa: Socio-demographic perspectives. Cape Town: HSRC Press: 43-59.

Amoateng, A. and Kalule-Sabiti, I. (2008). Socio-economic correlates of the incidence of extended household living in South Africa. Southern African Journal of Demography 11(1): 75-102.

Amoateng, A. and Richter, L. (2007). Social and economic context of families and households in South Africa. In: Amoateng, A. and Heaton, T. (eds.). Families and households in post-apartheid South Africa: Socio-demographic perspectives. Cape Town: HSRC Press: 1-25.

Bekker, B., Eberhard, A., Gaunt, T., and Marquard, A. (2008). South Africa's rapid electrification programme: Policy, institutional, planning, financing and technical innovations. Energy Policy 36(8): 3125-3127. doi:10.1016/j.enpol.2008.04.014.

Bhorat, H. and van der Westhuizen, C. (2013). Non-monetary dimensions of well-being in South Africa, 1993-2004: A post-apartheid dividend? Development Southern Africa 30(3): 295-314. doi:10.1080/0376835X.2013.817308.

Brown, M., Daniels, R., Villiers, L., Leibbrandt, M., and Woolard, I. (2012). National Income Dynamics Study Wave 2 user manual. Cape Town: Southern Africa Labour and Development Research Unit.

Casale, D., Muller, C., and Posel, D. (2004). 'Two million net new jobs:' A reconsideration of the rise in employment in South Africa: 1995-2003. South African Journal of Economics 72(5): 978-1002. doi:10.1111/j.1813-6982.2004.tb00141.x.

Collinson, M., Mokoena, O., Mgiba, N., Kahn, K., Tollman, S., Garenne, M., Herbst, K., Malomane, E., and Shackleton, S. (2002). Agincourt DSS, South Africa. In: Populations and their health in developing countries, Volume 1: Population, health and survival at INDEPTH sites. Ottawa: IDRC Press: 197-206.

Collinson, M., Tollman, S., Garenne, M., and Kahn, K. (2001). Temporary female migration and labour force participation in rural South Africa. Johannesburg: University 
Wittenberg, Collinson \& Harris: Decomposing changes in household measures

of the Witwatersrand. (Agincourt Health and Population Unit working paper).

Dinkelman, T. (2011). The effects of rural electrification on employment: New evidence from South Africa. American Economic Review 101(7): 3078-3108. doi:10.1257/aer. 101.7.3078.

Gaunt, C. (2005). Meeting electrification's social objectives in South Africa, and implications for developing countries. Energy Policy 33(10): 1309-1317. doi:10.1016/ j.enpol.2003.12.007.

Harris, T. (2016). Household electricity access and household dynamics. [Master's dissertation]. Cape Town: School of Economics, University of Cape Town.

Hosegood, V., Benzler, J., and Solarsh, G. (2005). Population mobility and household dynamics in rural South Africa: Implications for demographic and health research. Southern African Journal of Demography 10(1/2): 43-68.

Hundenborn, J., Leibbrandt, M., and Woolard, I. (2016). Drivers of inequality in South Africa. Cape Town: Southern African Labour and Development Research Unit. (SALDRU working paper 194).

Kahn, K., Collinson, M., Gómez-Olivé, F., Mokoena, O., Twine, R., Mee, P., Afolabi, S., Clark, B., Kabudula, C., Khosa, A., Khoza, S., Shabangu, M., Silaule, B., Tibane, J., Wagner, R., Garenne, M., Clark, S., and Tollman, S. (2012). Profile: Agincourt Health and Socio-demographic Surveillance System. International Journal Of Epidemiology 41(4): 988-1001. doi:10.1093/ije/dys115.

Kerr, A., Lam, D., and Wittenberg, M. (2013). Post-Apartheid Labour Market Series 1994-2012, version 2.1 [dataset]. [electronic resource]. Cape Town: DataFirst. http://www.datafirst.uct.ac.za/catalogue3/index.php/catalog/434.

Kerr, A. and Wittenberg, M. (2015). Sampling methodology and field work changes in the October Household Surveys and Labour Force Surveys. Development Southern Africa 32(5): 603-612. doi:10.1080/0376835X.2015.1044079.

Kuijsten, A. (1995). Recent trends in household and family structures in Europe: An overview. In: van Imhoff, E., Kuijsten, A., Hooimeijer, P., and van Wissen, L. (eds.). Household demography and household modeling. New York: Plenum: 53-84. doi:10.1007/978-1-4757-5424-7_3.

Leibbrandt, M., Finn, A., and Woolard, I. (2012). Describing and decomposing postapartheid income inequality in South Africa. Development Southern Africa 29(1): 1934. doi:10.1080/0376835X.2012.645639.

Leibbrandt, M., Woolard, I., and de Villiers, L. (2009). Methodology: Report on NIDS wave 1. Cape Town: University of Cape Town, National Income Dynamics 
Study. (Technical paper 1).

Leibbrandt, M., Woolard, I., Finn, A., and Argent, J. (2010). Trends in South African income distribution and poverty since the fall of Apartheid. Paris: OECD Publishing. (OECD Social, Employment and Migration working papers 101).

Machemedze, T., Kerr, A., and Wittenberg, M. (2014). Recalibrating the OHSs to adjust for sampling changes. Cape Town: University of Cape Town, DataFirst. (Technical paper 28).

Niehaus, I. (2001). Witchcraft, power and politics: Exploring the occult in the South African Lowveld. London: Pluto Press.

Peracchi, F. (2002). The European Community Household panel: A review. Empirical Economics 27(1): 63-90. doi:10.1007/s181-002-8359-0.

Posel, D., Fairburn, J., and Lund, F. (2006). Labour migration and households: A reconsideration of the effects of the social pension on labour supply in South Africa. Economic Modelling 23: 836-853. doi:10.1016/j.econmod.2005.10.010.

Rose, D. (1995). Household panel studies: An overview. Innovation: The European Journal of Social Sciences 8(1): 7-24.

Russell, M. (2003a). Are urban black families nuclear? A comparative study of black and white South African family norms. Social Dynamics 29(2): 153-176. doi:10.1080/ 02533950308628679.

Russell, M. (2003b). Understanding Black households: The problem. Social Dynamics 29(2): 5-47. doi:10.1080/02533950308628674.

Schatz, E., Madhavan, S., Collinson, M., Gómez-Olivé, X., and Ralston, M. (2015). Dependent or productive? A new approach to understanding the social positioning of older South Africans through living arrangements. Research on Aging 37(6): 581-605. doi: $10.1177 / 0164027514545976$.

Tollman, S. (1999). The Agincourt field site: Evolution and current status. South African Journal of Medicine 89(8): 855-857.

Tollman, S., Herbst, K., Garenne, M., Gear, J., and Kahn, K. (1999). The Agincourt demographic and health study: Site description, baseline findings and implications. South African Journal of Medicine 89(8): 858-864.

Udjo, E. (2015). Projecting population, numbers of households and dwelling units in South Africa 2011-2021. African Population Studies 29(1): 1510-1524. doi:10.11564/ 29-1-698.

Wittenberg, M. and Collinson, M. (2007). Household transitions in rural South 
Wittenberg, Collinson \& Harris: Decomposing changes in household measures

Africa, 1996-2003. Scandinavian Journal of Public Health 35(Suppl. 69): 130-137. doi:10.1080/14034950701355429.

Ziehl, S. (2001). Documenting changing family patterns in South Africa: Are census data of any value? African Sociological Review 5(2): 36-62. doi:10.4314/asr.v5i2.23190. 